\title{
BIOLOGIA Y PERSPECTIVA DE MICROORGANISMOS ENDÓFITOS ASOCIADOS A PLANTAS
}

\section{BIOLOGY AND PERSPECTIVE OF ENDOPHYTE MICROORGANISMS ASSOCIATED WITH PLANTS}

\section{PEREZ, C. ALEXANDER ${ }^{{ }^{*}}$ Dr, ROJAS, S. JOHANNA ${ }^{2}$ M.Sc. VALE, M. HELSON ${ }^{3}$ Dr.}

\author{
${ }^{1}$ Universidad de Sucre, Facultad de Ciencias Agropecuarias, Grupo \\ Bioprospección Agropecuaria. ${ }^{2}$ Universidad de Sucre, Facultad de Educación y \\ Ciencias, Grupo Bioprospección Agropecuaria. ${ }^{3}$ Universidad de de Brasilia, \\ departamento de Fitopatología, Brasil. Correspondencia *: \\ Alexander.perez@unisucre.edu.co
}

\section{RESUMEN}

Las bacterias endófitas residen en tejidos de las plantas, principalmente espacios intercelulares, raramente en espacios intracelulares y dentro de tejidos vasculares sin causar síntomas de enfermedad en la planta. Las discusiones sobre el origen de las bacterias endófitas y la forma de penetración, además de los mecanismos de colonización, consideran la hipótesis de que se originaron desde semillas, de la rizosfera, de microflora de filoplano o de material utilizado para la propagación vegetativa. La penetración en la planta puede ocurrir por estomas, heridas, áreas de emergencia de raíces laterales, siendo que estas bacterias pueden producir enzimas hidrolíticas capaces de degradar la pared celular de los vegetales. Estudios moleculares reciente sobre diversidad de bacterias endófitas han revelado una alta riqueza de filotipos, que promueven el crecimiento de las planta, suprimen fitopatógenos, ayudan a remover contaminantes, solubilizan fosfato y contribuyen a la asimilación biológica de nitrógeno. El objetivo de esta revisión es dar a conocer la evolución, ecología, diversidad, funcionalidad y técnicas fisiológicas y moleculares para el aislamiento de bacterias endófitas asociadas a tejidos de plantas.

Palabras claves: Bacterias, endófitas, diversidad, planta

\section{ABSTRACT}

The endophyte bacteria inhabit plant tissues mainly in intercellular spaces, rarely in intracellular spaces and inside vascular tissues without causing symptoms of disease in plants. Debates on the origin of the endophyte bacteria and the form of penetration, besides the colonization mechanisms, consider the hypothesis that they were originated from seeds, microflora rizosphere of 
"phylloplane" or material used for plant propagation. The penetration in the plant might take place by stomas, wounds, emergence areas in lateral roots, allowing these bacteria to produce hydrolytic enzymes able to degrade the vegetables cell wall. Recent molecular studies on the diversity of endophyte bacteria have revealed a high affluence of phylotypes promoting the plant growth, suppressing phytopathogens, helping to remove contaminants, dissolving phosphate and contributing to the biological nitrogen assimilation. The objective of this review is to show the evolution, ecology, diversity, function and physiological and molecular techniques for the isolation of endophyte bacteria associated with plant tissues.

Key word: Bacteria, Endophyte, diversity, plant.

\section{Origen y evolución de endófitas}

Las primeras evidencias de asociación entre microorganismos endófitos y plantas, se originaron de observaciones en tejidos y hojas fosilizadas, lo que soporta la inferencia de que la asociación planta-endófito pudo haber ocurrido junto con la aparición de las primeras plantas en la tierra (STROBEL, 2003; HUA WEl et al., 2006). Como resultado de esa larga asociación es posible que algunos de estos microorganismos endófitos hayan adquirido un sistema genético para transferir información desde la planta hospedera ha ellos, o viceversa. Este posiblemente seria un mecanismo rápido y seguro de adaptación a diferentes ambientes y a la planta hospedera, a ejemplo de rutas bioquímicas que resultan en la producción de compuestos químicos y metabolitos secundarios en las plantas asociadas a los endófitos (GERMAINE, et al., 2004; TSAVKELOVA et al., 2007).

El concepto de que los endófitos son microorganismos establecidos en los tejidos internos de la epidermis (KLOEPPER et al., 1992) es actualmente expreso como la asociación biológica en que los microorganismos colonizan tejidos internos vivos de las plantas, sin causar ningún efecto negativo inmediato o daño aparente a la planta (BACON y WHITE, 2000).

Las bacterias endófitas son reconocidas como las aisladas de tejidos de plantas desinfectadas superficialmente 0 , de su interior, y que no causan síntomas visibles de enfermedad en la planta (HALLMANN et al., 1997; SAKIYAMA et al., 2001). Estas bacterias son encontradas principalmente en los espacios intercelulares de los tejidos $y$, con menor frecuencia, intracelularmente y en tejidos vasculares, sin causar síntomas de enfermedad (HUREK et al., 1994; BELL et al., 1995). Bacterias endófitas se pueden tornar patógenas sobre ciertas condiciones, e inclusive en función del genótipo de la planta hospedera (MISAGHI y DONNDELINGER, 1990). Estudios también señalan que las bacterias endófitas interactúan con patógenos (HUANG, 1991; 
BACON y HILTON, 1997; SESSITCH et al., 2002), promueven el crecimiento en las plantas (TSAVKELOVA et al., 2007), aumentan la resistencia a enfermedades (CHANWAY, 1998), contribuyen a la fijación biológica de nitrógeno (JIMENEZ-SALGADO et al. 1997; ESTRADA et al., 2002) y brindan protección contra patógenos mediante la producción y síntesis de metabolitos secundarios (BROOKS et al., 1995; BERG et al., 2005; TAN y ZOU, 2001; LONG et al., 2003; SHIOMl et al., 2006) y biorremediación (NEWMAN y REYNOLDS, 2005).

Recientemente, aislados de bacterias endófitas de Populus fueron caracterizadas por su uso potencial en proceso de fitorremediación (MOORE et al., 2006), a ejemplo del uso de Burkholderia cepacia G4 que incrementa la tolerancia de las plantas al tolueno (VAN DER LELIE, 2005) y de Methylobacterium populum sp nov. BJ001 como participante de la biodegradacion de compuestos, tales como: 2,4,6-trinitrotolueno (TNT), hexahydro-1,3,5-trinitro-1,3,5-triazina (HMX) y octahidro-1,3,5-7-tetranitro-1,3,57-tetrazocine (RDX) (VAN et al., 2004).

Las discusiones sobre el origen de las bacterias endófitas y la forma de penetración, además de los mecanismos de colonización, consideran la hipótesis de que se originaron de semillas, de la rizosfera, de filoplano o de material utilizado para la propagación vegetativa (REINHOLD-HUREK y HUREK, 1998). La penetración en la planta puede ocurrir por los estomas, heridas, áreas de emergencia de raíces laterales, siendo que éstas endofitas pueden producir enzimas hidrolíticas capaces de degradar la pared celular de los vegetales (McCULLY, 2002). Esta hipótesis fue derivada del análisis de datos que demuestran la presencia de enzimas celulíticas y pectinolíticas producidas por bacterias endofíticas, a ejemplo de Azoarcus sp. (HUREK et al., 1994), Azospirillum irakense (KHAMMAS y KAISER, 1991) y Pseudomonas fluorescens (QUADT-HALLMANN et al., 1997). La colonización y la distribución de bacterias endófitas en la planta pueden ser influenciadas por la interacción con otros organismos asociados a la planta, a ejemplo de nematodos parásitos, o por características propias de su hospedero (HIRANO y HUPPER, 2002).

\section{Ecología de endófitas}

La planta es un hábitat dinámico en que diversos factores pueden influenciar la estructura y la composición de la comunidad bacteriana. En cultivos in vitro de tomate, la colonización de las bacterias endofíticas varían con las alteraciones de la densidad de inóculo, temperatura de cultivo y genotipo de hospedero (PILLAY y NORWAK, 1997). Las variaciones estaciónales, el tipo de tejido vegetal (MOCALI et al., 2003), especie y cultivares de hospedero y la interacción con otros microorganismos benéficos (ARAÚJO et al., 2002) también pueden influenciar el patrón de colonización. 
La densidad poblacional de bacterias endófitas es menor que la de patogénicas $y$, por lo menos algunas de ellas, no inducen respuesta de hipersensibilidad y por eso no son reconocidas por la planta. Evolutivamente, los endófitos aparecen como intermediarios entre bacterias saprofitas y patogénicas de plantas. De modo general, la microbiota endófita y la estructura dinámica es influenciada por los factores bióticos y abióticos que también afectan al suelo y la planta hospedera (HALLMMAN et al., 1997).

Las bacterias endófitas han sido aisladas de plantas monocotiledóneas y dicotiledóneas comerciales, en especies de árboles forestales (BROOKS et al., 1994, CANKAR et al., 2005), frutales (WHITESIDES y SPOTTS, 1991; VEGA et al., 2005; LACAVA et al., 2006), plantas herbáceas como caña de azúcar (JACOBS et al., 1985), soya (KUKLINSKY-SOBRAL et al., 2004) y orquídeas (TSAVKELOVA et al., 2007).

\section{Aislamiento e identificación de endófitas}

La diversidad de bacterias endófitas representa apenas una pequeña fracción de la diversidad total existente en la naturaleza. Informaciones derivadas de estudios comparativos apuntan para el hecho de que apenas una pequeña fracción de los microorganismos en la naturaleza (entre $0,1 \%$ a $10 \%$, dependiendo del hábitat) es cultivable mediante empleo de métodos microbiológicos convencionales (RANJARD et al., 2000; GREEN y BOHANNAN, 2006).

Hasta hace pocos años, la mayoría de los métodos para el estudio de la diversidad microbiana eran realizados a través del crecimiento en medios de cultivos. Esos métodos generan informaciones sobre los grupos de microorganismos viables y cultivables dentro de la comunidad. Varias limitaciones están asociadas al cultivo de los microorganismos que pueden influir en la verdadera diversidad microbiana de la comunidad, entre las cuales la dificultad en desalojar bacterias unidas a partículas de suelo y biofilme, selección del medio de crecimiento, condiciones de crecimiento, tales como: temperatura, luz, $\mathrm{pH}$, interacciones negativas entre las colonias de microorganismos y la presencia de microorganismos con tasa de crecimiento rápido (KIRT et al., 2004).

Otro método para el estudio de la diversidad microbiana por técnicas dependientes del cultivo incluyen el perfil fisiológico de las comunidades microbianas, la cual es determinado por la capacidad de esas comunidades en utilizar diferentes fuentes de carbono in vitro. Esa metodología fue desarrollada inicialmente utilizando microplacas Biolog ${ }^{\mathrm{TM}}$ conteniendo 95 fuentes diferentes de carbono, sal de tetrazolio y un control negativo. Actualmente, es 
comercializado el Ecoplate Biolog ${ }^{\mathrm{TM}}$ conteniendo 31 fuentes de carbono diferentes de las encontradas normalmente en el ambiente, un control negativo y tres repeticiones. Métodos que determinan el perfil fisiológico han sido utilizados para evaluar la diversidad metabólica potencial de comunidades microbianas en diferentes ambientes. Estos son selectivos para organismos cultivables que crecen en condiciones de laboratorio y favorecen a los microorganismos de rápido crecimiento (KIRK et al., 2004).

El análisis de la diversidad y la estructura de comunidades pueden incluir la determinación de perfiles de la composición de lípidos extraídos de muestras ambientales. El análisis de ésteres metílicos de ácidos grasos (FAME) consiste en la esterificación de los lípidos extraídos de muestras, seguida de separación e identificación por medio de cromatografía de gas. Los FAMEs son identificados por el tiempo de retención en la columna, comparativamente a los tiempos de retención de los patrones sometidos al mismo proceso. La cuantificación de cada compuesto es realizada con base en la determinación de las áreas de los picos correspondiente en el cromatograma (TÓTOLA y CHAER, 2002, KIRK et al., 2004).

Los métodos mas recientes exploran características del rDNA que, juntos con la bioinformática y los análisis estadísticos, son consideradas herramientas valiosas para estudios de caracterización y estructura de las comunidades microbianas en diferentes ambientes (NOCKER et al., 2007). Entre las técnicas moleculares comúnmente empleadas se encuentran, entre otros: clonación y secuenciamiento de rDNA 16S (ZINNIEL et al., 2002); hibridación DNA-DNA (JIMENEZ-SALGADO et al., 1997); análisis de restricción del DNA ribosomal amplificado-ARDRA (MOCALI et al., 2003); análisis de espaciador intergénico ribosomal-RISA; electroforesis en gel de gradiente desnaturante (DGGE) (GARBEVA et al., 2001, SESSITSCH et al., 2002, LAÇAVA et al., 2006).

La técnica de DGGE ha sido aplicada para el análisis de comunidades de bacterias en ambientes complejos, tales como suelo y rizosfera, en la detección de variaciones de la comunidad en presencia de agroquímicos, estados nutricionales y fisiológicos de plantas hospederas (YANG y CROWLEY, 2000) y en el estudio de comunidades de bacterias endófitas asociadas a plantas (GARBEVA et al., 2001; SESSITSCH et al., 2002; LAÇAVA et al., 2005).

La clonación y el secuenciamiento de rDNA 16S (HEAD et al., 1998) es considerado unos de los métodos apropiados para explorar la diversidad microbiana en ambientes naturales. Esta técnica ofrece alta resolución filogenética, permite la generación de datos para la identificación de especies o la determinación de similaridad con especies conocidas, mediante el uso de secuencias depositadas en bancos de datos acreditados (NOCKER et al., 2007). 
El secuenciamento directo de amplicons es una técnica cada vez más utilizada por dispensar la necesidad de clonación y construcción de librerías genómicas, siendo las secuencias de DNA obtenidas directamente a partir de pequeñas cantidades de muestras ambientales. Bacterias endófitas aisladas de tejidos aéreos de cuatro especies de cultivo agrícola y 27 especies de plantas de planicie fueron identificadas por medio de secuenciamento directo, y las comparaciones con las secuencias registradas correspondieron a: Bacillus subtilis, Corynebacterium glutamicum, Microbacterium smegmatis, Cellumonas flavigena, Curtobacterium luteum y C. citreum, Clavibacter michiganensis y varias especies de Microbacterium (ZINNIEL et al., 2002). Básicamente, la técnica consiste en la extracción del DNA, amplificación de rDNA 16S y eliminación de los residuos de primers y dNTPs por medio de técnicas de precipitación, cromatografía de intercambio iónico, filtración en gel con el empleo de Kits y, finalmente, el secuenciamiento (RAO, 2007).

\section{Diversidad de endófitas}

Las bacterias están indisolublemente asociadas a las plantas como patogénicas, epifitas, endófitas, simbióticas y antagónicas. Muchas forman asociaciones íntimas con las plantas y forman grupos diversos filogenéticamente representados por especies pertenecientes a los principales taxones. Las bacterias asociadas a las plantas típicamente intercambian señales con su hospedero y poseen diversos mecanismos para adaptación y colonización (PRESTON et al., 1998). Aspectos importantes de la diversidad de bacterias en el ecosistema incluyen los diferentes procesos que estos realizan, la complejidad de la interacción y el número de niveles tróficos que los componen. En los últimos años, ha despertado intereses cada vez mayor aspectos relacionados con la composición, estructura y función de comunidades bacterianas $y$, en particular las unidades fundamentales de las cuales están compuestas (WARD, 2006). Muchos de los phyllum descritos para bacterias son conocidos a partir de estudios en cultivo a nivel de laboratorio, entretanto un número diverso de ellas son identificados por medio de secuenciamento de rDNA $16 \mathrm{~S}$ de bacterias colectadas de hábitat naturales. Hasta hoy existen descritos 24 phyllum de bacterias, que presentan una gran diversidad en términos de morfología, fisiología e historia evolutiva (TORSIVIK y OVREAS, 2002; GORRITY et al., 2004).

El dominio Bacteria comprende una variedad de individuos patogénicos, así como millares de especies no-patogénicas. Constituyen un grupo de microorganismos de ocurrencia cosmopolita en los más diversos hábitats, y presentan gran diversidad de vías metabólicas, agrupando organismos especializados en la utilización de compuestos orgánicos e inorgánicos. 
La densidad poblacional de bacterias endófitas es altamente variable, depende de la especie de bacteria y el genotipo de la planta hospedera, además del estado de desarrollo del planta, la densidad del inoculo y las condiciones ambientales (PILLAY y NORWAK, 1998). Estudios moleculares recientes han revelado una gran riqueza de filotipos de bacterias endófitas asociados a deferentes especies de plantas, aunque esta lista no es completa debido a que continuamente existe reporte de nuevas endófitas, en ella se ubican los principales Phyllum de estos microorganismos y las especies de plantas donde han sido aisladas e identificadas (tabla 1).

\section{Perspectivas}

Desde el inicio de la era de la ecogenómica (NELSON et al., 2007), ha surgido en la comunidad científica a nivel mundial la búsqueda de informaciones sobre la funcionalidad de microorganismos in situ. En este contexto, el desarrollo de investigaciones direccionadas a la expresión de proteínas a partir de microbios nativos en el ambiente es uno de los desafíos que se tiene para entender el papel de esto organismos en la tierra. Esta funcionalidad microbiana podrá ser elucidad por medio de analsis de transcripción de RNA (metranscriptoma) y expresión de proteínas (metaproteoma) de todas las comunidades bacterianas en el ambiente. Esto es considerado una etapa fundamental para comprender los mecanismos de regulación metabólica (metaboloma) y la exploración de nuevos genes funcionales asociados ambientes y plantas especificas (MARON et al., 2006).

Las bacterias endófitas son consideradas como modelo de estudio de expresión génica en su nicho natural o hábitat dentro de las plantas (MARON et al., 2006). Sin embargo, cuestiones básicas sobre la diversidad microbiana existente en plantas comerciales, así como la estructura de esas comunidades y la funcionalidad en diferentes especies vegetales, localizadas en diversos ambientes geográficamente definidos, deben ser objeto de investigaciones modernas en lo referente a bacterias endófitas y productividad. Proyectos genómicos están siendo desarrollado sobre algunas bacterias endófitas tales como Azoarcus spp. (BATTISTONI et al., 2005), Herbaspirillum sp., Gluconazobacter diazotrophicus y Klebsiella spp., quienes pueden ser de gran ayuda para la comprensión de las interacciones molecular entre las endófitas y las plantas (ROSENBLUETH y MARTINEZ-ROMERO, et al., 2006). 
Tabla 1. Reporte de bacterias endófitas y plantas donde fueron aislada.

\begin{tabular}{|c|c|c|c|}
\hline Endófitas & Phyllum & Planta & Referencia \\
\hline & a-Proteobacteria & & \\
\hline $\begin{array}{l}\text { Azorhizobium caulinodans } \\
\text { Azospirillum brasilense }\end{array}$ & & $\begin{array}{l}\text { Arroz } \\
\text { Banana }\end{array}$ & $\begin{array}{l}\text { ENGELHARD et al. } 2000 \\
\text { WEBER et al. } 1999\end{array}$ \\
\hline Azospirillum amazonense & & Banana, piña & WEBER et al. 1999 \\
\hline Bradyrhizobium japonicum & & Arroz & CHANTREUIL et al. 2000 \\
\hline Gluconacetobacter diazotrophicus & & Caña de azúcar, café & $\begin{array}{l}\text { CAVALCANTE Y DÖBEREINER 1988; } \\
\text { JIMÉNEZ-SALGADO et al. } 1997\end{array}$ \\
\hline Methylobacterium mesophilicuma & & Cítricos & ARAUJO et al. 2002 \\
\hline Methylobacterium extorquens & & Pino, cítricos & $\begin{array}{l}\text { ARAUJO et al. 2002; PIRTTILÄ et al. } \\
2004\end{array}$ \\
\hline Rhizobium leguminosarum & & Arroz & YANNI et al. 1997 \\
\hline $\begin{array}{l}\text { Rhizobium (Agrobacterium) } \\
\text { radiobacter }\end{array}$ & & Zanahoria, arroz & SURETTE et al. 2003 \\
\hline Sinorhizobium meliloti & & Batata & REITER et al. 2003 \\
\hline \multirow[t]{2}{*}{ Sphingomonas paucimobilisa } & & Arroz & ENGELHARD et al. 2000 \\
\hline & $\beta$-Proteobacteria & & \\
\hline Azoarcus sp & & Arroz., pasto & $\begin{array}{l}\text { ENGELHARD et al. 2000; REINHOLD- } \\
\text { HUREK et al. } 1993\end{array}$ \\
\hline Burkholderia pickettiia & & Maíz & MCINROY y KLOEPPER 1995 \\
\hline Burkholderia cepacia & & Citricos & ARAUJO et al. 2001; BARAC et al. 2004 \\
\hline Burkholderia sp. & & Banana, piña, arroz & $\begin{array}{l}\text { WEBER et al. } 1999 \\
\text { ENGELHARD et al. } 2000\end{array}$ \\
\hline Chromobacterium violaceuma & & Arroz & PHILLIPS et al. 2000 \\
\hline Herbaspirillum seropedicae & & $\begin{array}{l}\text { Caña de azúcar, arroz, maíz, } \\
\text { sorgo,banana }\end{array}$ & $\begin{array}{l}\text { OLIVARES et al. 1996; WEBER et al. } \\
1999\end{array}$ \\
\hline Herbaspirillum rubrisulbalbicans & y -Proteobacteria & Caña de azúcar & OLIVARES et al. 1996 \\
\hline Citrobacter $\mathrm{sp}$ & & Banana & MARTÍNEZ et al. 2003 \\
\hline Enterobacter spp & & Maíz & MCINROY y KLOEPPER 1995 \\
\hline Enterobacter sakazakiia & & Soya & KUKLINSKY-SOBRAL et al. 2004 \\
\hline Enterobacter cloacaea & & Cítricos, maíz & $\begin{array}{l}\text { ARAUJO et al. 2002; } \\
\text { HINTON et al. } 1995\end{array}$ \\
\hline Enterobacter agglomeransa & & Soya & KUKLINSKY-SOBRAL et al. 2004 \\
\hline Enterobacter asburiae & & Batata & ASIS y ADACHI 2003 \\
\hline Erwinia sp. & & Soya & KUKLINSKY-SOBRAL et al. 2004 \\
\hline Escherichia coli & & Lechuga & INGHAM et al. 2005 \\
\hline Klebsiella sp. & & Trigo, batata, arroz & $\begin{array}{l}\text { ENGELHARD et al. 2000; } \\
\text { INIGUEZ et al. 2004; REITER et al. } 2003\end{array}$ \\
\hline Klebsiella pneumoniaeb & & Soya & KUKLINSKY-SOBRAL et al. 2004 \\
\hline Klebsiella variicolab & & $\begin{array}{l}\text { Banano, arroz, Maíz, Caña de } \\
\text { azúcar }\end{array}$ & ROSENBLUETH et al. 2004. \\
\hline Klebsiella terrigenaa & & Zanahoria & SURETTE et al. 2003 \\
\hline Klebsiella oxytocab & & Soya & KUKLINSKY-SOBRAL et al. 2004 \\
\hline Pantoea sp. & & Arroz, soya & $\begin{array}{l}\text { KUKLINSKY-SOBRAL et al. 2004; } \\
\text { VERMA et al. } 2004\end{array}$ \\
\hline Pantoea agglomerans & & Cítrico, batata & $\begin{array}{l}\text { ARAUJO et al. } 2001,2002 \\
\text { ASIS y ADACHI } 2003\end{array}$ \\
\hline Pseudomonas chlororaphis & & Zanahoria & $\begin{array}{l}\text { STURZ y KIMPINSKI 2004; } \\
\text { SURETTE et al. } 2003\end{array}$ \\
\hline Pseudomonas putida & & Zanahoria & SURETTE et al. 2003 \\
\hline Pseudomonas fluorescens & & Zanahoria & SURETTE et al. 2003 \\
\hline Pseudomonas citronellolis & & Soya & KUKLINSKY-SOBRAL et al. 2004 \\
\hline Pseudomonas synxantha & & Pino & PIRTTILÄ et al. 2004 \\
\hline Salmonella entérica & & Zanahoria, rabano, tomate & $\begin{array}{l}\text { COOLEY et al. 2003; GUO et al. 2002; } \\
\text { ISLAM et al. } 2004\end{array}$ \\
\hline Serratia sp. & & Arroz & SANDHIYA et al. 2005 \\
\hline Serratia marcescensa & & Arroz & GYANESHWAR et al. 2001 \\
\hline \multirow[t]{2}{*}{ Stenotrophomonasa } & & Pasto & DALTON et al. 2004 \\
\hline & Firmicutes & Cítricos & ARAUJO et al. 2001, 2002 \\
\hline Bacillus megaterium & & Maíz, zanahoria, cítricos & $\begin{array}{l}\text { ARAUJO et al. 2001; } \\
\text { MCINROY Y KLOEPPER 1995; } \\
\text { SURETTE et al. } 2003\end{array}$ \\
\hline Clostridium sp & & Pastura & MIYAMOTO et al. 2004 \\
\hline Paenibacillus odorifer & & Batata & REITER et al. 2003 \\
\hline Staphylococcus saprophyticus & & Zanahoria & SURETTE et al. 2003 \\
\hline \multirow{3}{*}{ Sphingobacterium sp } & Bacteroides & & \\
\hline & & Arroz & PHILLIPS et al. 2000 \\
\hline & Actinobacteria & & \\
\hline Arthrobacter globiformis & & Maíz & CHELIUS y TRIPLETT 2000a \\
\hline Curtobacterium flaccumfaciens & & Cítricos & ARAUJO et al. 2002 \\
\hline Kocuria varians & & Caléndula & STURZ y KIMPINSKI 2004 \\
\hline Microbacterium esteraromaticum & & Caléndula & STURZ y KIMPINSKI 2004 \\
\hline Microbacterium testaceum & & Maíz & ZINNIEL et al. 2002 \\
\hline Mycobacterium sp. & & Trigo, pino & $\begin{array}{l}\text { CONN Y FRANCO 2004; } \\
\text { PIRTTILÄ et al. } 2005\end{array}$ \\
\hline Nocardia sp. & & Cítricos & ARAUJO et al. 2002 \\
\hline Streptomyces & & Trigo & COOMBS y FRANCO 2003a \\
\hline
\end{tabular}

Fuente: ROSENBLUETH y MARTINEZ-ROMERO, (2006). 


\section{Agradecimientos}

Agradecimiento a la Universidad Federal de Vişosa, Brasil sobre los conocimientos, aislamiento y técnicas moleculares para la identificación de bacterias endófitas.

\section{Referencias}

ARAUJO, W. L., MACCHERONI, W., JR., AGUILAR-VILDOSO, C. I., BARROSO, P. A. V., SARIDAKIS, H. O.; AZEVEDO, J. L. 2001. Variability and interactions between endophytic bacteria and fungi isolated from leaf tissues of citrus rootstocks. Canadian Journal of Microbiology. 47:229-236.

ARAUJO, W. L., MARCON, J., MACCHERONI, W., JR., VAN ELSAS, J. D., VAN VUURDE, J. W. L., AND AZEVEDO, J. L. 2002. Diversity of endophytic bacterial populations and their interaction with Xylella fastidiosa in citrus plants. Applied Environmental Microbiology. 68:4906-4914.

ASIS, C. A., ADACHI, K. 2003. Isolation of endophytic diazotroph Pantoea agglomerans and nondiazotroph Enterobacter asburiae from sweet potato stem in Japan. Letter in Applied Microbiology. 38:19-23.

BACON, W.C., HINTON, D. M.1997. Isolation and culture of endophytic bacteria and fungi. In: HURST, C. et al. (Eds.). Manual of environmental microbiology. p.413-421.

BACON, C. W.; WHITE J. F. 2000. Microbial Endhopytes. Marcel Dekker Inc., New York, N.Y.

BARAK, J. D., GORSKI, L., NARAGHI-ARANI, P., CHARKOWSKI, A. O. 2005. Salmonella enterica virulence genes are required for bacterial attachment to plant tissue. Applied Environmental Microbiology. 71:5685-5691.

BATTISTONI, F., BARTELS, D., KAISER, O., MARIE REAMON-BUETTNER, S., HUREK, T.; REINHOLD-HUREK, B. 2005. Physical map of the Azoarcus sp. strain $\mathrm{BH} 72$ genome based on a bacterial artificial chromosome library as a platform for genome sequencing and functional analysis. FEMS (Fed. Eur. Microbiol. Soc.) Microbiology Letter. 249:233-240.

BELL, C.R., G. A. DICKIE, W. L. HARVEY, J. M. CHAIN. 1995. Edophytic bacteria in grapevine. Canadian Journal of Microbiology. V. 41, p. 46-53.

BERG G, KRECHEL A, DITZ M, SIKORA A., ULRICH A., HALLMANN J. 2005. Endophytic and ectophytic potato-associated bacterial communities differ in structure and antagonistic function against plant pathogenic fungi, FEMS Microbiology Ecology. 5:1215-229. 
BROOKS, D.S., GONZALEZ, C.F., APPEL, D.N., FILER, T.H. 1994. Evaluation of endophytic bacteria as potential biological control agents for oak wilt. Biology Conservation. 4:373-381.

CANKAR K., KRAIGHER H., RAVNIKAR M., RUPNIK M. 2005. Bacterial endophytes from seeds of Norway spruce (Picea abies L. Karst). FEMS Microbiology Letters. V 244, p.341-345.

CAVALCANTE, V. A., DÖBEREINER, J. 1988. A new acid-tolerant nitrogen fixing bacterium associated with sugarcane. Plant Soil. 108:23-31.

CHANWAY, C. P. 1998. Bacterial endophytes: ecological and practical implications. Sydowia, v 50, p. 149-170.

CHAINTREUIL, C., GIRAUD, E., PRIN, Y., LORQUIN, J., BA, A., GILLIS, M., DE LAJUDIE, P., DREYFUS, B. 2000. Photosynthetic bradyrhizobia are natural endophytes of the African wild rice Oryza breviligulata. Applied Environmental Microbiology. 66:5437-5447.

CHELIUS, M. K.; TRIPLETT, E. W. 2000. Diazotrophic endophytes associated with maize. Pages 779-791 in: Prokaryotic Nitrogen Fixation; A Model System for Analysis of a Biological Process. Horizon Scientific Press, Wymondham, U.K.

CONN, V. M., FRANCO, C. M. M. 2004. Analysis of the endophytic actinobacterial population in the roots of wheat (Triticum aestivum L.) by terminal restriction fragment length polymorphism and sequencing of 16S rRNA clones. Applied Environmental Microbiology. 70:1787-1794.

COOLEY, M. B., MILLER, W. G., MANDRELL, R. E. 2003. Colonization of Arabidopsis thaliana with Salmonella enterica and enterohemorrhagic Escherichia coli O157:H7 and competition by Enterobacter asburiae. Applied Environmental Microbiology. 69:4915-4926.

COOMBS, J. T., FRANCO, C. M. M. 2003a. Isolation and identification of actinobacteria isolated from surface-sterilized wheat roots. Applied Environonmental Microbiology. 69:5303-5308.

DALTON, D. A., KRAMER, S., AZIOS, N., FUSARO, S., CAHILL, E., ENNEDY, C. 2004. Endophytic nitrogen fixation in dune grasses (Ammophila arenaria and Elymus mollis) from Oregon. FEMS (Fed. Eur. Microbiol. Soc.) Microbiology Ecology. 49:469-479.

ENGELHARD, M., HUREK, T., REINHOLD-HUREK, B. 2000. Preferential occurrence of diazotrophic endophytes, Azoarcus spp., in wild rice species and land races of Oryza sativa in comparison with modern races. Environmental Microbiology. 2:131-41. 
ESTRADA, P., MAVINGUI, P., COURNOYER, B., FONTAINE, F., BALANDREAU, J., CABALLEROMELLADO, J. 2002. A N2-fixing endophytic Burkholderia sp. associated with maize plants cultivated in Mexico. Canadian Journal of Microbiology. V 48, P. 285-294.

GARBEVA, P.; VAN O.; VAN, V., VAN E. 2001. Análysis of endophytic bacterial communities of potato by planning and denaturing gradient gel electrophoresis (DGGE) of $16 \mathrm{~s}$ rDNA based fragment. Microbiology Ecology. V 41, 362-383.

GERMAINE K., KEOGH E., GARCIA-CABELLOS G., BORREMANS B., VAN DER LELIE D., BARAC T., OEYEN L., VANGRONSVELD J., PORTEOUS MOORE F., MOORE E. R.B. , CAMPBELCOLIN D. L , RYAN D., OWLING D.N. 2004. Colonisation of poplar trees by gfp expressing bacterial endophytes. FEMS Microbiology Ecology. V 48, 109-118.

GREEN, J., BOHANNAN, B. 2006. Spatial scaling of microbial biodiversity. Microbial ecology, V. 21 n. 9, 501-507.

GORRITY, G.; BELL, J.; LILIBURN, T. Taxonomic outline of the Prokaryotes Bergey's Manual ${ }^{\circledR}$ of Systematic Bacteriology. 2. ed., New York, 2004.

GYANESHWAR, P., JAMES, E. K., MATHAN, N., REDDY, P. M., REINHOLDHUREK, B., LADHA, J. K. 2001. Endophytic colonization of rice by a diazotrophic strain of Serratia marcescens. Journal of Bacteriology. 183:26342645.

HALLMANN,J.,QUADT-HALLMANN, A., MAHAFFEE, W.F. KLOEPPER,J.W.1997. Bacterial endophytes in agricultural crops. Canadian Journal Microbiology. v.43, p.895-914.

HEAD L M., SAUNDERS J.R. PICKUP R.W. 1998. Microbial Evolution, Diversity, and Ecology: A Decade of Ribossomal RNA Analysis of Uncultivated Microorganisms. Microbial Ecology. V 35, p.1-21.

HIRANO, S., S HUPPER. 2000. Bacteria in the leaf Ecosytem with emphasis on Pseudomona syringae- a pathogen, Ice nucleus and Epiphytec Microbiology and Molecular Biology Rewiew. v.64, p 624-653.

HINTON, D. M., BACON, C. W. 1995. Enterobacter cloacae is an endophytic symbiont of corn. Mycopathologia. V.129, p.117-125.

HUREK, T. REINHOLD-HUREK, B., VAN M., KELLENBERGER, E. 1994. Root colonization and systemic spreading of Azoarcus sp. Strain BH72 in grasses. Journal of Bacteriology. v.176, p.1913-1923.

HUANG, J.1991. Ultrastructure of bacterial penetration in plants. Annual Review of Phythopatology. v. 24, p.141-157.

HUA WEI Z., YOUG CH.S., REN X.T. 2006. Biology and chemistry of endophytes. Natural Product Reports. 23, 753-771. 
INGHAM, S. C., FANSLAU, M. A., ENGEL, R. A., BREUER, J. R., BREUER, J. E., WRIGHT, T. H., REITH-ROZELLE, J. K., ZHU, J. 2005. Evaluation of fertilization- to-planting and fertilization-to-harvest intervals for safe use of noncomposted bovine manure in Wisconsin vegetable production. Journal of Food Protection. 68:1134-1142.

INIGUEZ, A. L., DONG, Y., TRIPLETT, E. W. 2004. Nitrogen fixation in wheat provided by Klebsiella pneumoniae 342. Mololecular Plant-Microbe Interactions. 17:1078-1085.

ISLAM, M., MORGAN, J., DOYLE, M. P., PHATAK, S. C., MILLNER, P., JIANG, X. 2004. Fate of Salmonella enterica serovar Typhimurium on carrots and radishes grown in fields treated with contaminated manure composts or irrigation water. Applied Environmental Microbiology. V.70, p.2497-2502.

JIMÉNEZ-SALGADO, T., FUENTES-RAMIREZ, L. E., TAPIA-HERNANDEZ, A., MASCARUA-ESPARZA, M. A., MARTINEZ-ROMERO, E., CABALLEROMELLADO, J. 1997. Coffea arabica I., a new host plant for Acetobacter diazotrophicus, and isolation of other nitrogen-fixing acetobacteria. Applied Environmental Microbiology. 63:3676-3683.

JACOBS, M.J.; BUGBEE, W.M., GABRIELSON, D.A.1985. Enumeration, location, and characterization of endophytic bacteria within sugar beet roots. Canadian Journal of Botany. v.63, p. 1262-1265.

KHAMMAS, K.M., KAISER, P.1991. Characterization of a pectinolytic activity in Azospirillum irakense. Plant Soil. v.137, p 75-79.

KIRK, J.; BEAUDETTE, L.; HART, M.; MOUTOGLIS, P.; KLIROMONOS, J.; LEE, H.; TREVORS, J. Methods of studying soil microbial diversity. Journal of Microbiological Methods, v. 58, p. 169-188, 2004.

KLOEPPER, J.W., SCHIPPERS, B., BAKKER, P.A. 1992. Proposed limination of the term endorhizosphere. Phytopathology. 82:726-727.

KUKLINSKY-SOBRAL, J., ARAUJO, W. L., MENDES, R., GERALDI, I. O., PIZZIRANI-KLEINER, A. A., AZEVEDO, J. L. 2004. Isolation and characterization of soybean-associated bacteria and their potential for plant growth promotion. Environmental Microbiology. 6:1244-1251.

LACAVA, T. P.; DINI, A F.; ARAUJO, W.; AZEVEDO, J. 2006. Caracterização da comunidade de bactérias endofíticas de cítricos por isolamento, PCR especifica e DGGE. Pesquisa Agropecuária Brasileira, Brasília, v. 41, p. 637542.

LONG, H. H., FURUYA, N., KUROSE, D., TAKESHITA, M., TAKANAMI, Y. 2003. Isolation of endophytic bacteria from Solanum sp. and their antibacterial activity against plant pathogenic bacteria. Journal of the Faculty of Agriculture. Kyushu Univ., V. 48, P. 21-28. 
MACCULLEY, M.E. 2002. Niches for bacterium endophytes In crop plants: A plant Biologists view. Australian Journal of plant Physiology. v. 28, p.983-990.

MARON, P.; RANJARD, L.; MOUGEL, C.; LEMANCEAU, P. 2006. Metaproteomics: A new Approach for Studying Functional Microbial Ecology. Microbial Ecology, 53:486-493.

MARTíNEZ, L., CABALLERO, J., OROZCO, J., MARTíNEZ-ROMERO, E. 2003. Diazotrophic bacteria associated with banana (Musa spp.). Plant Soil. 257:35-47.

MCINROY, J. A., KLOEPPER, J. W. 1995. Survey of indigenous bacterial endophytes from cotton and sweet corn. Plant Soil. 173:337-342.

MIYAMOTO, T., KAWAHARA, M., MINAMISAWA, K. 2004. Novel endophytic nitrogen-fixing clostridia from the grass Miscanthus sinensis as revealed by terminal restriction fragment length polymorphism analysis. Applied Environmental Microbiology. 70:6580-6586.

MISAGHI, I.J., DONNDELINGER, C.R. 1990. Endophytic bacteria in symptomfree Cotton plants. Phytopathology. v.80, p. 808-811.

MOCALI S.; BERTELLI E.; DI C.; MENGONI A.; SFALANGA A.; VILIANI F.; CACIOTTI A., TEGLI S. S. G. 2003. Fluctuation of bacteria isolated from elm tissues during different seasons and from different plant organs. Research in Microbiology. v.154, p. $105-114$.

MOORE F. P.; BARAC T.; BORREMANS B.; OEYEN L.; VANGRONSVELD J.; VAN DER LELIE D.; CAMPBEL C. D., MOORE E. R.B. 2006. Endophytic bacterial diversity in poplar trees growing on a BTEX-contaminated site: The characterisation of isolates with potential to enhance phytoremediation. Systematic and Applied Microbiology. V. 29, p. 539-556.

NELSON K.E., METHE B.A., GEORGE A. KOWALCHUK. 2007. Microbial Environmental Genomics. Microbial Ecology. V 53, p. 367-368.

NEWMAN, L. A., REYNOLDS, C. M. 2005. Bacteria and phytoremediation: new uses for endophytic bacteria in plants. Trends in Biotechnology. V. 23 n.1 January.

NOCKER A., BURR M., CAMPER A. 2007. Genotypic Microbial Community Profiling: A Critical Technical Review. Microbial Ecology. P. 1-10.

OLIVARES, F. L., BALDANI, V. L. D., REIS, V. M., BALDANI, J. I., DOBEREINER, J. 1996. Occurrence of the endophytic diazotrophs Herbaspirillum spp. in roots, stems, and leaves, predominantly of Gramineae. Biology and Fertility of Soils. 21:197-200.

PHILLIPS, D.A., MARTÍNEZ-ROMERO, E., YANG, G. P., JOSEPH, C. M. 2000. Release of nitrogen: A key trait in selecting bacterial endophytes for 
agronomically useful nitrogen fixation. Pages 205-217 in: The Quest for Nitrogen Fixation in Rice. J. K. Ladha and P. M. Reddy (eds.). International Rice Research Institute, Manila, The Philippines.

PILLAY, V., K., NORWARK J. 1997. Inoculam, density, temperature, and genetype effect on in vitro growth promotion and epiphytec and endophytec colonization of tomato (Lycopersicon esculentum L.), seeding inoculated with a Pseudomonal bacterium. Canadian Journal of Microbiology, v 43, p.354-361.

PIRTTILÄ, A. M., JOENSUU, P., POSPIECH, H., JALONEN, J., HOHTOLA, A. 2004. Bud endophytes of Scots pine produce adenine derivatives and other compounds that affect morphology and mitigate browning of callus cultures. Physiology Plantarum 121:305-312.

PRESTON, G.; HAUBOLD, B.; RAINEY, P. 1998. Bacterial genomics and adaptation to life plants: implications for the evolution of pathogenicity and symbioses. Current Opinion in Microbiology, v. 1, p. 589-597.

QUADT-HALLMANN, A., BENHAMOU, N., KLOEPPER, J.W. 1997. Bacterial endophytes in cotton: mechanisms of entering the plant. Canadian Journal of Microbiology, v.43, p.577-582.

RANJARD, L.; POLY, F., NAZARET, S. 2000. Monitoring complex bacterial communities using culture-independente molecular techniques: Application to soil environmental. Research Microbiology, v. 151, p. 167-177.

RAO, V B. 2007. Strategies for direct sequencing of PCR-amplified DNA. Genome research. PCR Methods and Applications, v. 4, p. 15-23.

REITER, B., BÜRGMANN, H., BURG, K., SESSITSCH, A. 2003. Endophytic nifH gene diversity in African sweet potato. Canadian Journal of Microbiology. 49:549-555.

REINHOLD-HUREK, B., HUREK, T., GILLIS, M., HOSTE, B., VANCANNEYT, M., KERSTERS, K., DE-LEY, J. 1993. Azoarcus gen. nov., nitrogen-fixing proteobacteria associated with roots of Kallar grass (Leptochloa fusca (L.) Kunth), and description of two species, Azoarcus indigens sp. nov. and Azoarcus communis sp. nov. International Journal of Systematic Bacteriology. 43:574-584.

REINHOLD-HUKER, B., HUREK T.1998. Interactions of Grameneous plant with Azoarcus spp., and other diazotrophic, identification, localization and perspective to study their function. Critical Reviews in plant Science. V.17, p.2954.

ROSENBLUETH, M., MARTINEZ, L.,SILVA, J., MARTINEZ-ROMERO, E. 2004. Klebsiella variicola, a novel species with clinical and plant-associated isolates. Systematic and Applied Microbiology. 27:27-35. 
ROSENBLUETH M., MARTINEZ-ROMERO E.2006. Bacterial endophytes and their interaction with host.The American Phythopathological Society. MPMI. V. 19. n. 8 p. 827-837.

SAKIYAMA, C.C.H.; PAULA, E.M.; PEREIRA, P.C.; BORGES, A.C., SILVA D.O. 2001. Characterization of pectin lyase produced by an endophytic strain isolated from coffee cherries, Letter in Applied Microbiology. 333. p. 117-121.

SANDHIYA, G. S., SUGITHA, T. C. K., BALACHANDAR, D., KUMAR, K. 2005. Endophytic colonization and in planta nitrogen fixation by a diazotrophic Serratia sp. in rice. Indian Journal of Experimental Biology. 43:802-807.

SESSITSCH A., REITER B., PFEIFER U., WILHELM E. 2002. Cultivationindependent population analysis of bacterial endophytes in three potato varieties based on eubacterial and Actinomycetes-specific PCR of 16S rRNA genes. FEMS Microbiology Ecology. V. 39 , p. 23-32.

SHIOMI, H.; ALVES, S. H.; SOARES, I.; VIEIRA, F., WAGNER, B. 2006. Bioprospecting Endophytic Bacteria for Biological Control of Coffee leaf rust. Sci. Agric. v.63, n.1, p.32-39.

STROBEL GARY A. 2003. Endophytes as sources of bioactive products. Microbes and Infection. V. 5, p. 535-544.

STURZ, A., KIMPINSKI, J. 2004. Endoroot bacteria derived from marigolds (Tagetes spp.) can decrease soil population densities of rootlesion nematodes in the potato root zone. Plant Soil 262:241-249.

SURETTE, M. A., STURZ, A. V., LADA, R. R., NOWAK, J. 2003. Bacterial endophytes in processing carrots (Daucus carota L. var. sativus): Their localization, population density, biodiversity and their effects on plant growth. Plant Soil. 253:381-390.

TAN, R. X. \& ZOU X. W. 2001. Endophytes: A Rich source functional de metabolites. Nature Products. V. 18, p. $448-459$.

TÓTOLA, M. R.; CHAER, G. M. 2002. Microrganismos e processos microbiológicos como indicadores da qualidade do solo. Tópicos em Ciências do solo, Sociedade Brasileira de Ciências do Solo, Viçosa, v 2, p. 25-32.

TORSVIK, V.; OVREAS, L. 2005. Microbial diversity and function in soil: from genes to ecosystems. Current Opinion in Microbiology, v. 5, p. 240-245.

TSAVKELOVA E.A., CHERDYNTSEVA T.A., BOTINA S. G., NETRUSOV A.I. 2007. Bacteria associated with orchid roots and microbial production of auxin. Microbiological Research. V. 162, p. 69-76.

YANNI, Y. G., RIZK, R. Y., CORICH, V., SQUARTINI, A., NINKE, K., PHILIPHOLLINGSWORTH, S., ORGAMBIDE, G., DE BRUIJN, F., STOLTZFUS, J., 
BUCKLEY, D., SCHMIDT, T. M., MATEOS, P. F., LADHA, J. K., DAZZO, F. B. 1997. Natural endophytic association between Rhizobium leguminosarum bv.trifolii and rice roots and assessment of potential to promote rice growth. Plant Soil 194:99-114.

WARD, D. A. 2006. Microbiological perspective on microbial species. Microbes, v. 1 , n. 6 , p. $269-278$.

WEBER, O. B., BALDANI, V. L. D., TEIXEIRA, K. R. S., KIRCHHOF, G., BALDANI, J. I., DOBEREINER, J. 1999. Isolation and characterization of diazotrophic bacteria from banana and pineapple plants. Plant Soil 210:103113.

WHITESIDES, S.K., SPOTTS, R.A. 1991. Frequency, distribution, and characteristics of endophytic Pseudomonas syringe in pear trees. Phytopathology. V. 81, p. 453-457.

VAN A. 2004. Biodegradation of Nitro-Substituted Explosives 2,4,6Trinitrotoluene, Hexahydro-1,3,5-Trinitro-1,3,5-Triazine, and Octahydro-1,3,5,7Tetranitro-1,3,5-Tetrazocine by a Phytosymbiotic Methylobacterium sp. Associated with Poplar Tissues (Populus deltoides!nigra DN34). Applied Environmental Microbiology. V. 70, p. 508-517.

VEGA, F.; PAVA, R.M.; POSADA, F, BUYER, J. 2005. Endophytic bacteria in coffea arábica L., Journal Basic of Microbiology. 45 , 5, p. 371-380.

VAN DER LELIE D., BARAC T., TAGHAVI S., VANGRONSVELD J. 2005. Response to Newman. New uses of endophytic bacteria to improve phytoremediation. TRENDS in Biotechnology. V. 23, N. 1. 8-12.

VERMA, S. C., SINGH, A., CHOWDHURY, S. P., TRIPATHI, A. K. 2004. Endophytic colonization ability of two deep-water rice endophytes, Pantoea sp. and Ochrobactrum sp. using green fluorescent protein reporter. Biotechnology Letter. 26:425-429.

YANG CH-H., CROWLWY D. 2002. Rhizosphere Microbial Community Structure Relation to Root Location and Plant Iron Nutrional Status Applied Environmental Microbiology. V. 66, n. 1, p. 345-351.

ZINNIEL, D. K., LAMBRECHT, P., HARRIS, N. B., FENG, Z., KUCZMARSKI, D., HIGLEY, P., ISHIMARU, C. A., ARUNAKUMARI, A., BARLETTA, R. G, VIDAVER, A. K. 2002. Isolation and characterization of endophytic colonizing bacteria from agronomic crops and prairie plants. Applied Environmental Microbiology. 68:2198-2208. 